Article

\title{
External Validation of the ASTER GDEM2, GMTED2010 and CGIAR-CSI- SRTM v4.1 Free Access Digital Elevation Models (DEMs) in Tunisia and Algeria
}

\author{
Djamel Athmania ${ }^{1} *$ and Hammadi Achour ${ }^{2}{ }^{*}$
}

1 Département des Sciences de la Terre et de l’Univers, Faculté des Sciences Exactes, de la Nature et de la Vie, Université de Tébessa, Tébessa 12002, Algeria

2 Département de Génie Géologique, Ecole Nationale d'Ingénieurs de Sfax, Université de Sfax, Sfax 3038, Tunisia

* Authors to whom correspondence should be addressed; E-Mails: athmaniad@yahoo.fr (D.A.); hammadi.achour@gmail.com (H.A.); Tel.: +213-771-035-071 (D.A.); +216-2285-0006 (H.A.); Fax: +213-3749-7496 (D.A.).

Received: 24 February 2014; in revised form: 24 April 2014 / Accepted: 13 May 2014 / Published: 21 May 2014

Abstract: Digital Elevation Models (DEMs) including Advanced Spaceborne Thermal Emission and Reflection Radiometer-Global Digital Elevation Model (ASTER GDEM), Shuttle Radar Topography Mission (SRTM), and Global Multi-resolution Terrain Elevation Data 2010 (GMTED2010) are freely available for nearly the entire earth's surface. DEMs that are usually subject to errors need to be evaluated using reference elevation data of higher accuracy. This work was performed to assess the vertical accuracy of the ASTER GDEM version 2, (ASTER GDEM2), the Consultative Group on International Agriculture Research-Consortium for Spatial Information (CGIAR-CSI) SRTM version 4.1 (SRTM v4.1) and the systematic subsample GMTED2010, at their original spatial resolution, using Global Navigation Satellite Systems (GNSS) validation points. Two test sites, the Anaguid Saharan platform in southern Tunisia and the Tebessa basin in north eastern Algeria, were chosen for accuracy assessment of the above mentioned DEMs, based on geostatistical and statistical measurements. Within the geostatistical approach, empirical variograms of each DEM were compared with those of the GPS validation points. Statistical measures were computed from the elevation differences between the DEM pixel value and the corresponding GPS point. For each DEM, a Root Mean Square Error (RMSE) was determined for model validation. In addition, statistical tools such as frequency histograms and Q-Q plots were used to 
evaluate error distributions in each DEM. The results indicate that the vertical accuracy of SRTM model is much higher than ASTER GDEM2 and GMTED2010 for both sites. In Anaguid test site, the vertical accuracy of SRTM is estimated $3.6 \mathrm{~m}$ (in terms of RMSE) $5.3 \mathrm{~m}$ and $4.5 \mathrm{~m}$ for the ASTERGDEM2 and GMTED2010 DEMs, respectively. In Tebessa test site, the overall vertical accuracy shows a RMSE of $9.8 \mathrm{~m}, 8.3 \mathrm{~m}$ and $9.6 \mathrm{~m}$ for ASTER GDEM 2, SRTM and GMTED2010 DEM, respectively. This work is the first study to report the lower accuracy of ASTER GDEM2 compared to the GMTED2010 data.

Keywords: ASTER GDEM2; SRTM v4.1; GMTED2010; accuracy assessment; Tunisia; Algeria

\section{Introduction}

Digital Elevation Model (DEM) and its derivative attributes (slope, curvature, roughness, local relief, etc.) constitute important parameters for an assessment of any process using digital terrain analysis. These morphometric parameters are commonly used in various applications including flood simulation [1], dune volume calculation [2], volcanic hazards mapping [3], seismic wave propagation [4], soil erosion mapping [5] and relative tectonic activity modeling [6]. Summaries of DEM applications in hydrological, geomorphological, and biological applications can be found in Moore et al. [7].

DEMs can be generated using different techniques such as air-borne and satellite-borne stereoscopic photogrammetry, RADAR/SAR interferometry, Light Detection and Ranging (LIDAR), and conventional surveying techniques (e.g., GPS, levelling). These techniques can be compared considering four aspects (i.e., price, accuracy, sampling density, pre-processing requirements). Each technique has its exclusive advantages but also some disadvantages; for a comprehensive review, see [8]. However, four main steps are encountered during the generation process of each DEM, regardless of which technology is used [9]: (1) data acquisition (source of elevation data); (2) resampling to required grid spacing (i.e., regular spaced grid); (3) interpolation to extract height of required point (i.e., in between two grid cell centers) and (4) DEM representation, editing and accuracy assessment. All of these steps mentioned above can introduce errors to the final DEM.

DEMs, like other spatial data sets, are subject to errors. Fisher and Tate [10] have investigated errors on gridded data sets and classified them into three main classes: (1) gross errors or blunders; (2) systematic errors and (3) random errors.

Causes and consequences of error in DEM have been widely explored [10]. A DEM quality depends on several factors including the acquisition system; methodology and algorithms; complexity of the terrain; grid spacing and data characteristics [11,12].

A variety of DEMs including Advanced Spaceborne Thermal Emission and Reflection Radiometer-Global Digital Elevation Model (ASTER GDEM), Shuttle Radar Topography Mission (SRTM), and Global Multi-resolution Terrain Elevation Data 2010 (GMTED2010) are freely available for the scientific community worldwide. Moreover, several projects are currently being undertaken to generate more precise DEMs. For instance, TanDEM-X mission was an efficient example that would 
cover the earth at $12 \mathrm{~m}$ grid spacing at an accuracy ranging between 4 and $10 \mathrm{~m}$ [13]. Scientific user can submit, via German Aerospace Center (DLR) home page, a scientific proposal in order to get cost-free DEM extracts. These DEM products may constitute an alternative for researchers in many developing countries with poor geospatial infrastructure [14], including Tunisia and Algeria. However, it is advisable, before attempting to extract different information from these models, to validate their accuracies and to understand the potential and limitations of using these datasets for a specific area.

Techniques for DEM validation have been widely investigated. Gonga-Saholiariliva et al. [15] gave an overview and mentioned various papers related to this topic. One approach of investigation uses the terms of internal and external validation depending on whether or not independent reference data are included in the assessment procedure [16]. Another way, often applied, is to group methods of DEM accuracy assessment into quantitative, based on statistics and accuracy measures, and into qualitative based on visual analysis.

Numerous studies were carried out for external validation of DEMs using various kinds of reference data and reference DEMs [17-34]. Those studies covered different continental areas, but not the north of Africa. For this reason, the present study was undertaken to assess the vertical accuracy of ASTER GDEM2, SRTM version 4.1 and GMTED2010 by comparing them to Global Navigation Satellite System (GNSS) validation points over two different geographical localities in Tunisia and Algeria.

\section{Test Sites and Datasets}

\subsection{Test Sites}

Two test sites, representing different elevation ranges and land cover types, were selected in this study: (1) the Anaguid Saharan platform in southern Tunisia and (2) the Tebessa basin in north eastern Algeria (Figure 1).

The Anaguid test site was chosen to represent area in a smooth landscape with elevation differences of approximately $150 \mathrm{~m}$. It is confined within a bounding area rectangle formed by the geographic coordinates $31^{\circ} 57^{\prime} \mathrm{N}$ to $31^{\circ} 44^{\prime} \mathrm{N}$ and $9^{\circ} 50^{\prime} \mathrm{E}$ to $9^{\circ} 33^{\prime} \mathrm{E}$, covering an area of $280 \mathrm{~km}^{2}$. Its topography is flat and denuded; the elevation ranges between $239 \mathrm{~m}$ and $383 \mathrm{~m}$ with an average of $288 \mathrm{~m}$ and standard deviation of $23 \mathrm{~m}$. The average slope, computed from SRTM DEM, varies between values of $4^{\circ}$ and $6^{\circ}\left(11^{\circ}\right.$ at maximum). Hard carbonaceous rocks and conglomerates deposits of the upper Cretaceous to the Neogene outcrop in the Anaguid site [35]

The Tebessa test site represents a high Atlas environment with rugged terrain, steep slopes and high elevation differences. It is located in north eastern Algeria within a bounding rectangle defined by the geographic coordinates $35^{\circ} 29^{\prime} 30^{\prime \prime} \mathrm{N}$ to $35^{\circ} 16^{\prime} 30^{\prime \prime} \mathrm{N}$ and $8^{\circ} 0^{\prime} 0^{\prime \prime} \mathrm{E}$ to $8^{\circ} 15^{\prime} 0^{\prime \prime} \mathrm{E}$, covering an area of $784 \mathrm{~km}^{2}$. The elevation ranges from approximately $762-1712 \mathrm{~m}$. The average slope, computed from SRTM DEM, is $18^{\circ}$, showing a threefold higher than the Anaguid Saharan platform site. The Tebessa test site includes several different geological formations deposited from the Triassic to the Quaternary, which support different types of landforms such as low rolling hills, and steep mountain slopes [36]. Bare ground, grasslands and urban areas are the predominant landcover with forests occupying mountain slopes at approximately $1250 \mathrm{~m}$ a.s.l. (Figure 2). 
Figure 1. Location of the test sites plotted on a shaded relief map obtained from SRTM DEMs.

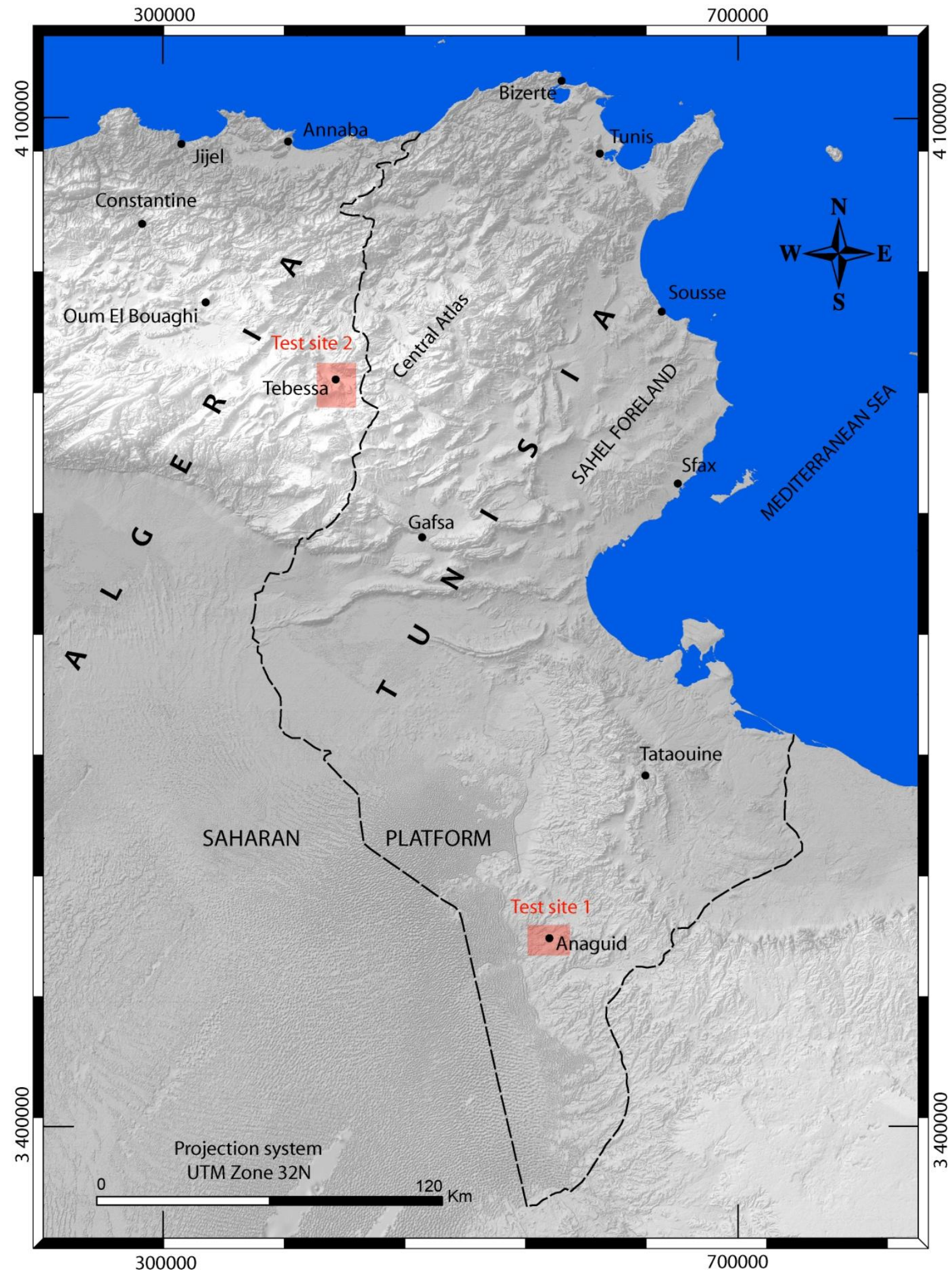


Figure 2. Landscape characteristics of the (a) Anaguid Saharan platform and (b) Tebessa Basin. Note the GPS base station photo in (a).

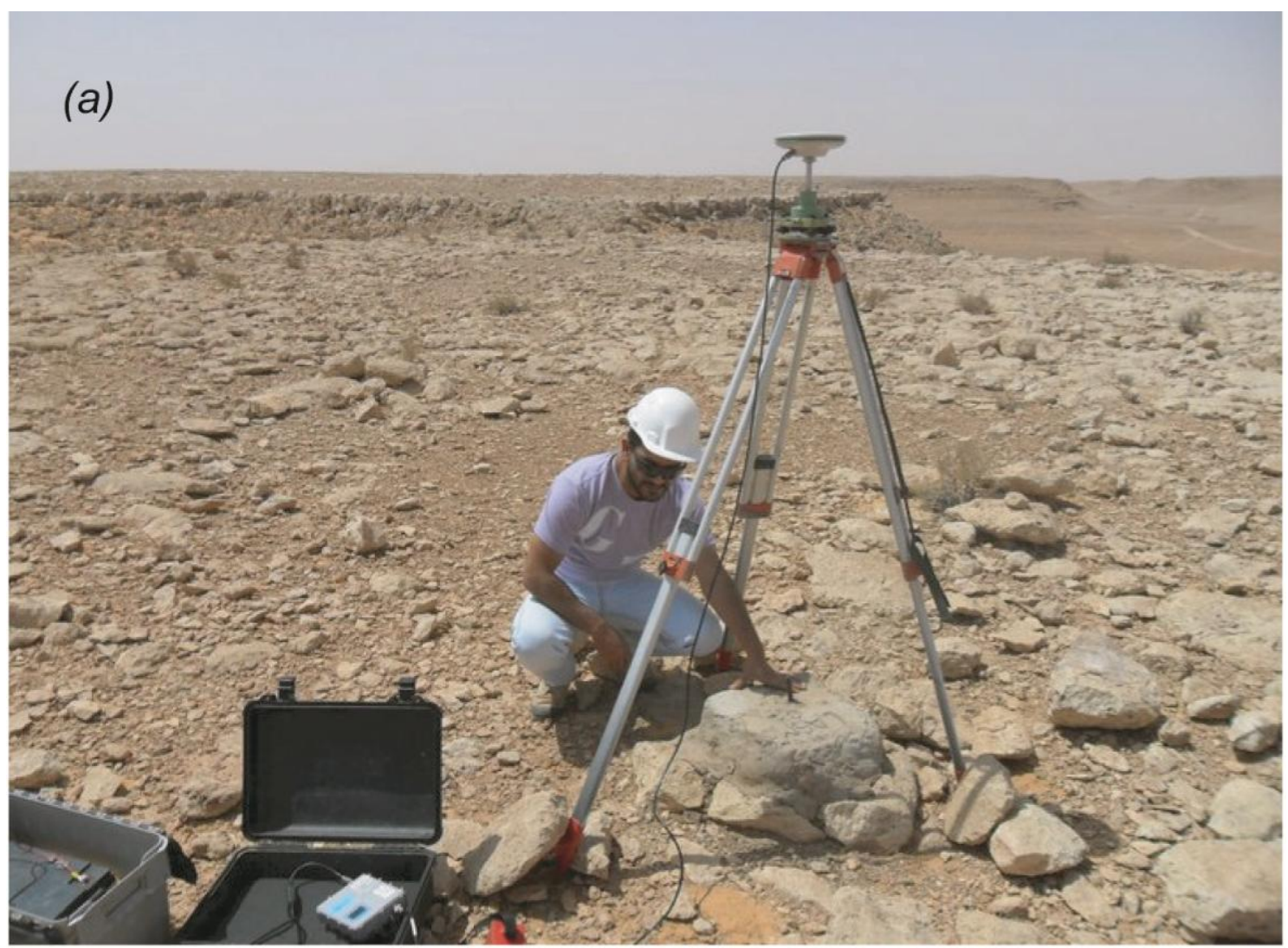

(b)

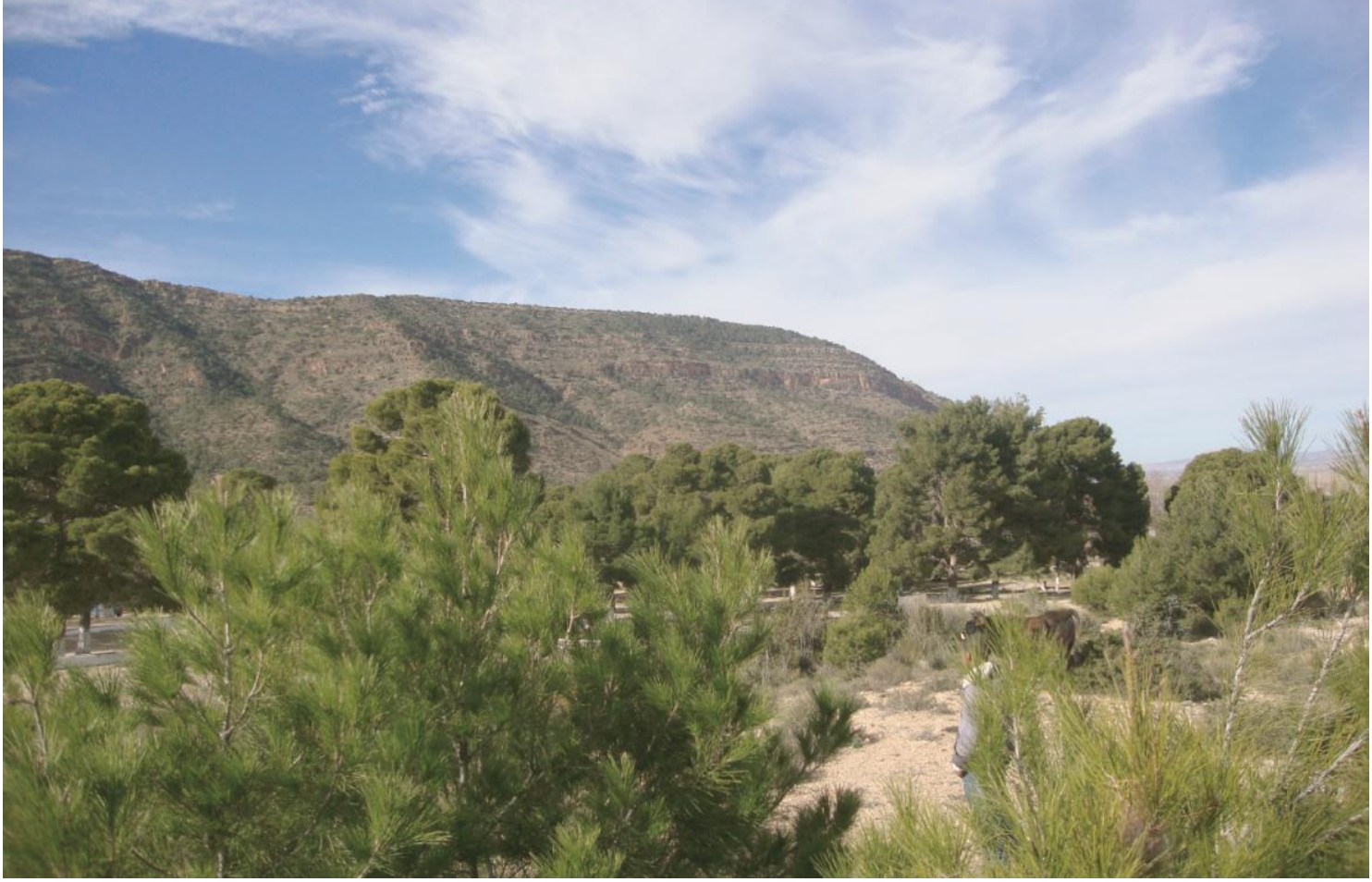




\subsection{Datasets}

\subsubsection{Available DEMs}

Three open source DEMs with different precision and coverage were used for the study; (1) Advanced Spaceborne Thermal Emission and Reflection Radiometer-Global Digital Elevation Model version 2 (ASTER GDEM2); (2) the Consultative Group for International Agriculture Research Consortium for Spatial Information Shuttle Radar Topographic Mission version 4.1 (CGIAR-CSI-SRTM v4.1) and (3) the systematic subsample Global Multi-resolution Terrain Elevation Data 2010 (GMTED2010). Further description of the source data is provided in Table 1 [37-39].

Table 1. Input source data characteristics.

\begin{tabular}{|c|c|c|c|}
\hline Data & $\begin{array}{l}\text { ASTER } \\
\text { GDEM2 }\end{array}$ & CGIAR-CSI SRTM v.4.1 & GMTED2010 \\
\hline Acquisition technique & $\begin{array}{c}\text { Satellite stereo } \\
\text { images }\end{array}$ & $\begin{array}{l}\text { SAR Interferometry } \\
\text { (InSAR) }\end{array}$ & $\begin{array}{c}\text { Fusion of multisource } \\
\text { elevation data }\end{array}$ \\
\hline Format & GeoTIFF & GeoTIFF & GeoTIFF \\
\hline Vertical units & Integer meters & Integer meters & Integer meters \\
\hline Horizontal datum & WGS84 & WGS84 & WGS84 \\
\hline Vertical datum & EGM96 & EGM96 & EGM96 \\
\hline Projection system & Geographic & Geographic & Geographic \\
\hline Spatial resolution (arc-seconds) & 1 arc-second & 3 arc-seconds & 7.5 arc-seconds \\
\hline RMSE specification (m) & $8.86-18.31[37]$ & $16[38]$ & $23-36[39]$ \\
\hline
\end{tabular}

The Advanced Spaceborne Thermal Emission and Reflection Radiometer-Global Digital Elevation Model (ASTER GDEM) was developed jointly by the METI (Ministry of Economy, Trade, and Industry) of Japan and the NASA (National Aeronautics and Space Administration). It was released to the public and made freely available on 29 June 2009 [36]. The ASTER GDEM product is generated from automatic processing of 1.5 million stereo pairs by applying the stereo correlation methodology. The ASTER GDEM is provided at a one arc-second resolution (approximately $30 \mathrm{~m}$ ) and referenced to the World Geodetic System 1984 (WGS84). Elevations are computed with respect to the Earth Geopotential Model 1996 (EGM96) geoid. The absolute vertical accuracy of ASTER GDEM is $20 \mathrm{~m}$ at $95 \%$ confidence level. In 2011, a second data product (ASTER GDEM2) was introduced in which the original data were: (1) augmented with an additional 260,000 overlapping images, and (2) refined in order to decrease the incidence of data artifacts, improve the spatial resolution, and increase the accuracy of water body coverage [37]. The resulting DEM is available online through the Data Pool at the NASA Land Processes Distributed Active Archive Center (LP DAAC) [37], from which tiles No. $31 \mathrm{E} 009$ and 34E008 covering the Anaguid and Tebessa test sites respectively, were downloaded.

Shuttle Radar Topography Mission (SRTM) DEM represents a collaborative effort between the National Imagery and Mapping Agency (NIMA) and NASA of U.S. Data were collected over an 11-day mission in February 2000 and are available for approximately $80 \%$ of the globe (up to $60^{\circ}$ north and $56^{\circ}$ south). Elevations were measured via radar interferometry, using X-band and C-band Interferometric Synthetic Aperture Radar (InSAR) sensor $(5.6 \mathrm{~cm}$ and $5.3 \mathrm{~cm}$ wavelength, 
respectively). SRTM C-band data are available at 1 arc-second for USA and 3 arc-seconds outside of the USA. The absolute vertical height accuracy is $16 \mathrm{~m}$ and the absolute horizontal accuracy is $20 \mathrm{~m}$. Since its original release, SRTM has been updated in order to remove erroneous pixel values, better delineate water body boundaries, fill data voids, etc. [38]. The most recent SRTM product has been treated by Consultative Group for International Agriculture Research Consortium for Spatial Information (CGIAR-CSI) and is available online through the CGIAR-CSI download database [38], from which tiles No. 3609 and 3605 were downloaded.

\subsubsection{Reference Elevation Data}

The accuracy assessment of the DEMs requires a large number of checkpoints with high accuracy to obtain reliable measures. According to Maune [40], the accuracy of the checkpoints should be at least three times more accurate than the DEM elevations. The American Society of Photogrammetry and Remote Sensing (ASPRS) recommended a minimum of 20 checkpoints in each major land cover category. In the case of three landcover classes (e.g., open terrain, forested areas, and urban areas), a minimum of 60 checkpoints are required [41]. For the purpose of this study, the check points were collected using Global Navigation Satellite Systems (GNSS) survey techniques.

Figure 3. Data used for Anaguid test site. (a) Location of the Anaguid Saharan platform, (b) RTK-DGPS reference data plotted on ASTER GDEM2, (c) SRTM v.4.1 and (d) systematic subsample GMTED 2010.
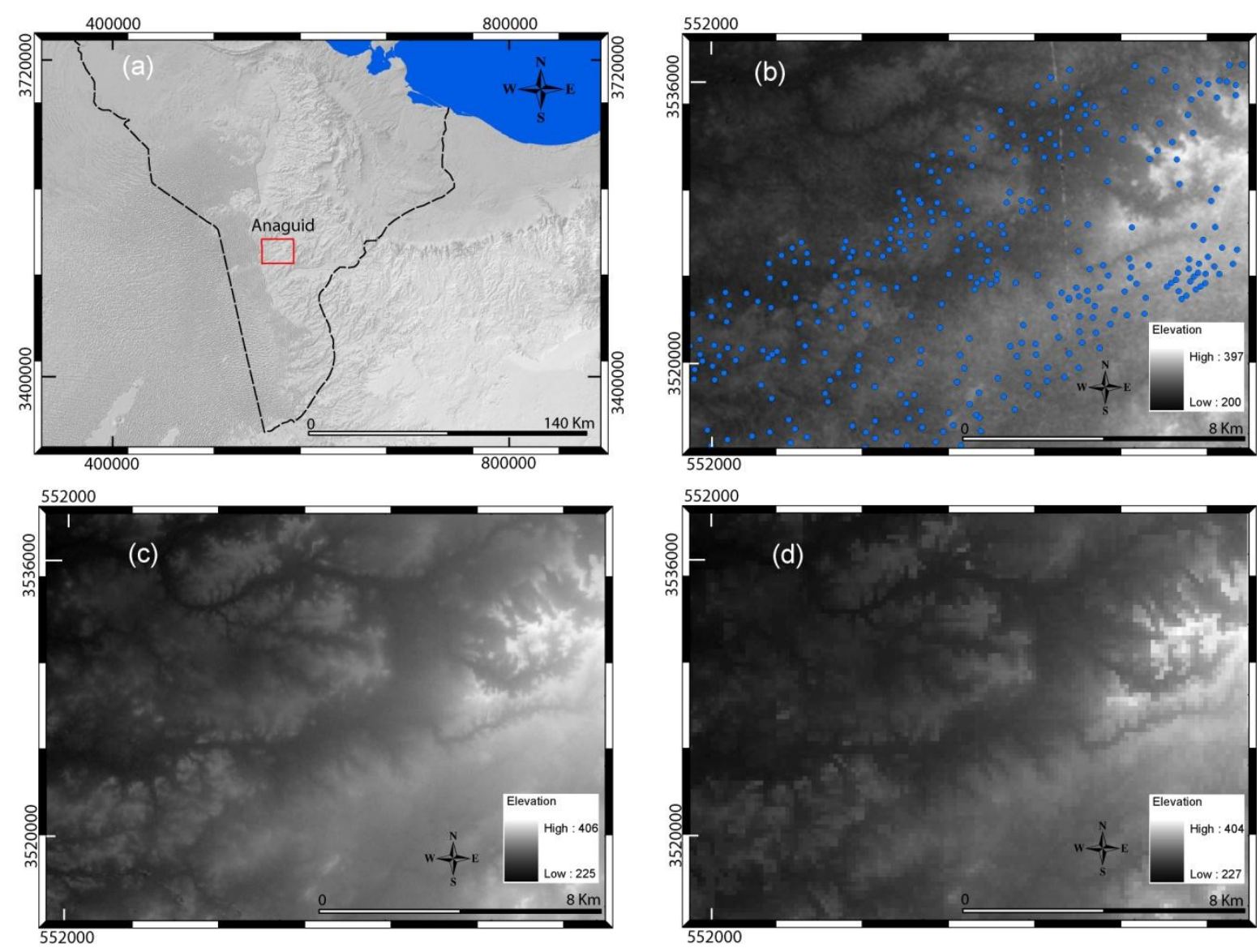
For Anaguid test site (Figure 3b), GNSS data were selected from an intensive 3D seismic survey conducted on February 2011. The acquisition technique is the Real Time Kinematic Differential Global Positioning System (RTK-DGPS), consisting of 328 GNSS points measured by Leica GRX 1200 series receivers. This moving mode provides a precision and accuracy of $20 \mathrm{~mm}+1 \mathrm{ppm}$ vertically and $10 \mathrm{~mm}+1 \mathrm{ppm}$ horizontally [42]. As for Tebessa test site (Figure 4b), the GNSS validation points are surveyed using Trimble GeoXH 6000 series receivers. They represented 60 ground control points (GCPs), measured using rapid static GNSS surveying techniques at decimeter-centimeter level accuracy [43]. However, the accuracy of GNSS data itself depended on many factors including the positional dilution of precision (PDOP) and the number of satellites in view (SV). Lower PDOP value indicated precise GPS data [44]. Those results were confirmed by Kaya and Saritas [45] who classified PDOP as (1) excellent if PDOP ranges between 1 and 2 and (2) good if PDOP varies between 2 and 5. Our results indicated a PDOP average value of 2.14 and 1.95 for Anaguid and Tebessa test sites, respectively. The average SV value was 7.82 and 9.25 for Anaguid and Tebessa, respectively (Figure 5).

Figure 4. Data used for Tebessa test site: (a) location of Tebessa basin, (b) GNSS data plotted on ASTER GDEM2, (c) SRTM v4.1 and (d) systematic subsample GMTED 2010.
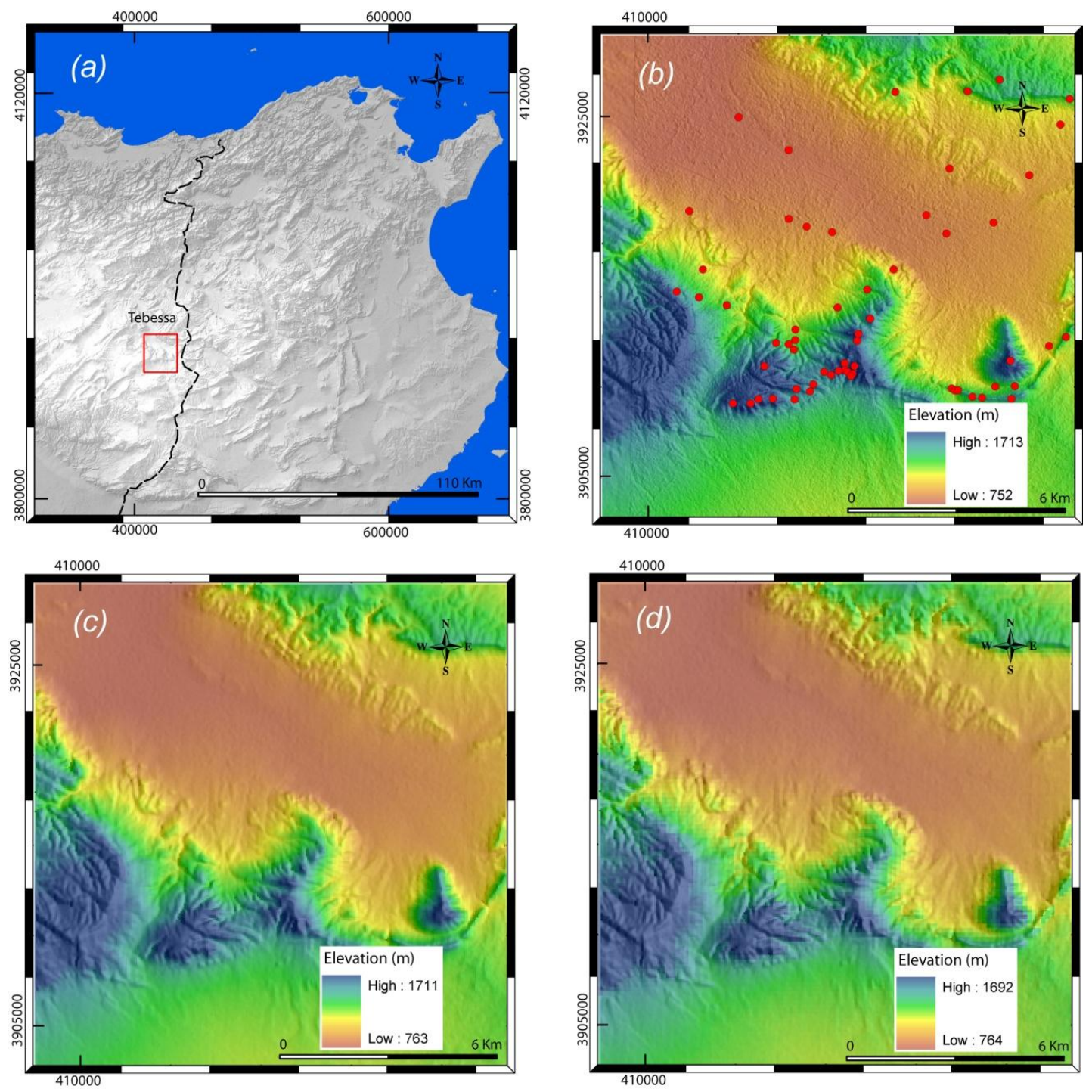
The Global Multi-resolution Terrain Elevation Data 2010 (GMTED2010) was produced by the U.S. Geological Survey (USGS) and the National Geospatial-Intelligence Agency (NGA) and became available in 2010 [39]. The mission's objective was the development of a global elevation model that replaces GTOPO 30 arc-seconds data (GTOPO30). GMTED2010 was derived from 11 raster based elevation sources using DEMs fusion technique. The GMTED2010 products were generated using the following aggregation methods: minimum elevation, maximum elevation, mean elevation, median elevation, standard deviation of elevation, systematic subsample, and breakline emphasis. Each product was generated at three separate resolutions of 30 arc-seconds, 15 arc-seconds, and 7.5 arc-seconds (approximately $1 \mathrm{~km}, 500 \mathrm{~m}$ and $250 \mathrm{~m}$, respectively). All products are in a geographic coordinate system referenced to the WGS84 horizontal datum, with the horizontal coordinates expressed in decimal degrees. The vertical units for the elevation values are integer meters, referenced to the EGM96 geoid as the vertical datum. In the present study, the systematic subsample product was selected because of its lower RMSE (ranging between 26 and $29 \mathrm{~m}$ ) in comparison with other GMTED2010 products [39].

Figure 5. Scatter plots of satellites in view values vs. PDOP for (a) Anaguid and (b) Tebessa test sites.
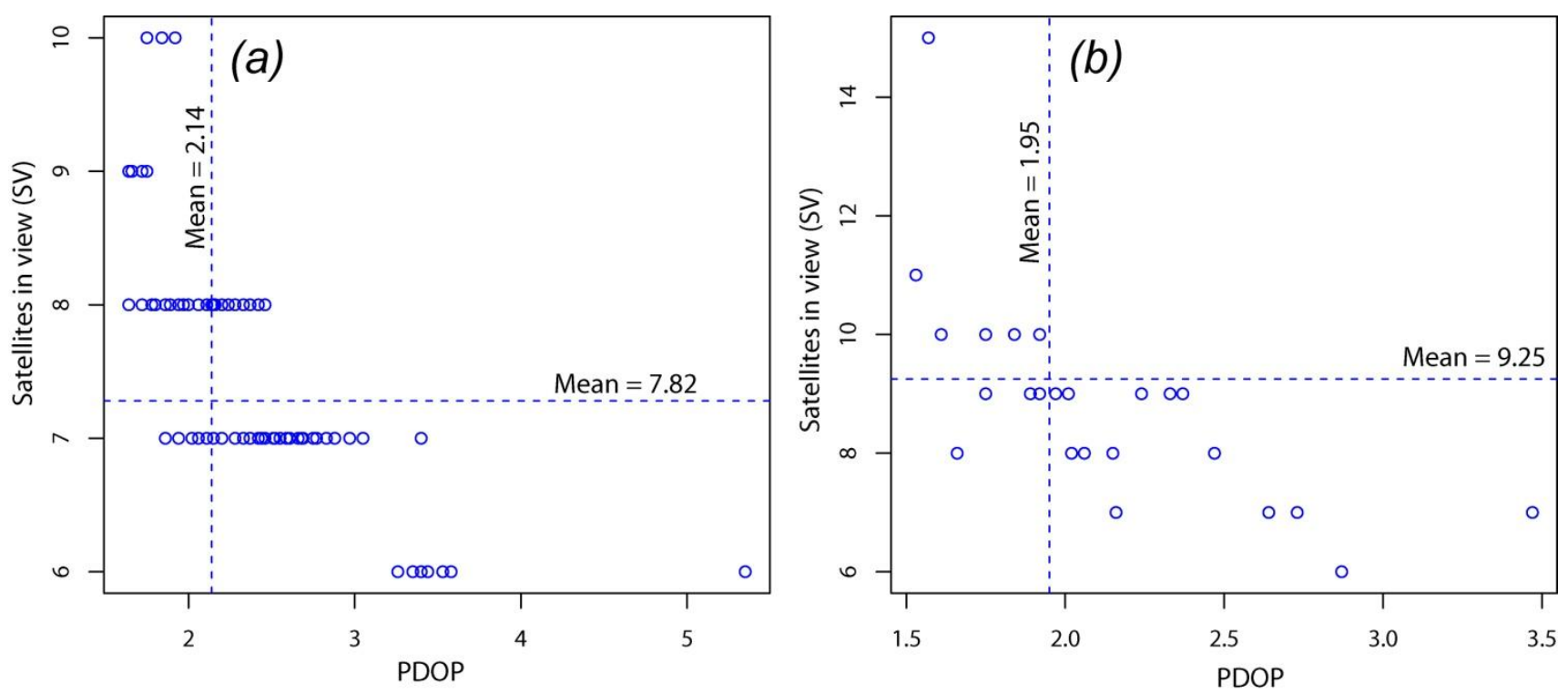

\section{Methods}

\subsection{Data Preparation and Processing}

After downloading the tiles of the ASTER GDEM2, SRTM v4.1 and GMTED2010, the three DEMs are projected to Universal Transverse Mercator (UTM) zone 32, and then clipped to the extent of each test site. As mentioned earlier, the three DEMs were given in terms of orthometric heights with respect to the geoid model computed from the Earth Geopotential Model 1996 (EGM96). However, the GNSS used Word Geodetic System 1984 (WGS84) as default vertical datum to compute the relative heights [45]. Therefore, GNSS geometric height had to be converted into orthometric height by subtracting the height of the geoid at each GNSS point location. For this reason, MS-DOS open 
source software developed by NASA Goddard Space Flight Center, the NIMA, and Ohio State University is used. This software computed geoid heights over land area with accuracy better than $1 \mathrm{~m}$, except in areas lacking accurate surface gravity data [46].

GNSS data are loaded into the ArcGIS software as vector points [47]. The "Extract Values to Points tool" in ArcGIS is used to extract the elevation value from the DEM at each control point location. The open source software R [48] is then used for model validation.

\subsection{Validation Methods}

In this study, the validation process was based on geostatistical and statistical measures. From a geostatistical point of view, the vertical accuracy of the three DEMs was evaluated by comparing the variogram of each DEM with that of GPS validation points. This step involved the computation of the semivariance between two sample points with respect to the distance that separates them. The gstat package for the statistics software $\mathrm{R}$ was used to produce the empirical variograms [49]. Mathematically, empirical variogram can be computed using the following equation ([50], Equation (1)):

$$
\lambda(\mathrm{h})=\frac{1}{2|\mathrm{~N}(\mathrm{~h})|} \sum_{\mathrm{N}(\mathrm{h})}\left(\mathrm{z}_{\mathrm{i}}-\mathrm{z}_{\mathrm{j}}\right)^{2}
$$

In Equation (1) $N(h)$ is the set of all pairwise Euclidean distances $i-j=h,|N(h)|$ is the number of distinct pairs in $\mathrm{N}(\mathrm{h})$, and $\mathrm{z}_{\mathrm{i}}$ and $\mathrm{z}_{\mathrm{j}}$ are data values at spatial locations $\mathrm{i}$ and $\mathrm{j}$, respectively.

From a statistical point of view, the vertical accuracy of the three DEM was assessed by computing the differences between the DEM pixel value and the corresponding GPS point. For each point, an elevation error was computed as the difference between explored and reference data (Equation (2)):

$$
\mathrm{Z}_{\text {dif }}=\mathrm{Z}_{\mathrm{ex}}-\mathrm{Z}_{\mathrm{ref}}
$$

In Equation (2), $Z_{\mathrm{dif}}$ is the elevation error, $\mathrm{Z}_{\mathrm{ex}}$ is the elevation of the explored DEM, and $\mathrm{Z}_{\mathrm{ref}}$ is the elevation of the GPS points. Positive differences represent locations where the DEM elevation exceeded the GPS point elevation; and, conversely, negative errors occur at locations where the DEM elevation was below the GPS elevation.

After that, the mean error (ME), standard deviation Error (STD), root mean square error (RMSE) and maximum (Max) and minimum (Min) error values were calculated as follows:

$$
\begin{gathered}
\mathrm{ME}=\sum \frac{\mathrm{Z}_{\mathrm{dif}}}{\mathrm{n}} \\
\mathrm{STD}= \pm \sqrt{\frac{\left(\mathrm{Z}_{\mathrm{dif}}-\mathrm{ME}\right)^{2}}{\mathrm{n}-1}} \\
\mathrm{RMSE}=\sqrt{\frac{\sum\left(\mathrm{Z}_{\mathrm{dif}}\right)^{2}}{\mathrm{n}}}
\end{gathered}
$$

STD and RMSE are measures of surface quality and provide insight into the distribution of deviations on either side of the mean value. The level of agreement between ASTER GDEM2, SRTM and GMTED2010 derived elevation values and GPS data is also evaluated in terms of linear regression and correlation. 
In order to describe and compare the error distributions in each DEM, a normality test is made. Quantile-quantile plots (Q-Q plots) are generated for visual inspection of normality. The Q-Q plot is a scatter plot with the quantiles of the observed values on the horizontal axis and the expected normal value on the vertical axis. A dataset with a best-fit linear relationship indicated that the observed values were normally distributed [51]. It is also possible to use statistical tests to investigate whether data originate from a normal distribution, but these tests are often rather sensitive in case of large data sets or outliers [52]. Therefore, visual methods are preferred. More details about normality test can be found in [53], who recommended visual methods as a component of good data analysis.

\section{Results and Discussions}

Figure 6 shows the empirical variograms of the elevation computed for each test site and for each elevation data source. It can easily be observed that all variograms showed similar trend, but with different sills. The SRTM variogram is much closer to the GNSS variogram than those of ASTER and GMTED2010 for both sites. The ASTER model presents a much lower sill variogram than other elevation data regardless of the relief zone. Therefore, the plotted variograms indicate the superior vertical accuracy of SRTM v4.1 followed by GMTED2010 and ASTER GDEM2 compared with the GNSS elevations data.

Figure 6. Empirical variograms of the three DEMs compared with that of GNSS elevations points for each test site: (a) Anaguid and (b) Tebessa. The red, black, blue and green variograms represent GNSS, SRTM v4.1, GMTED2010 and ASTER GDEM2, respectively.
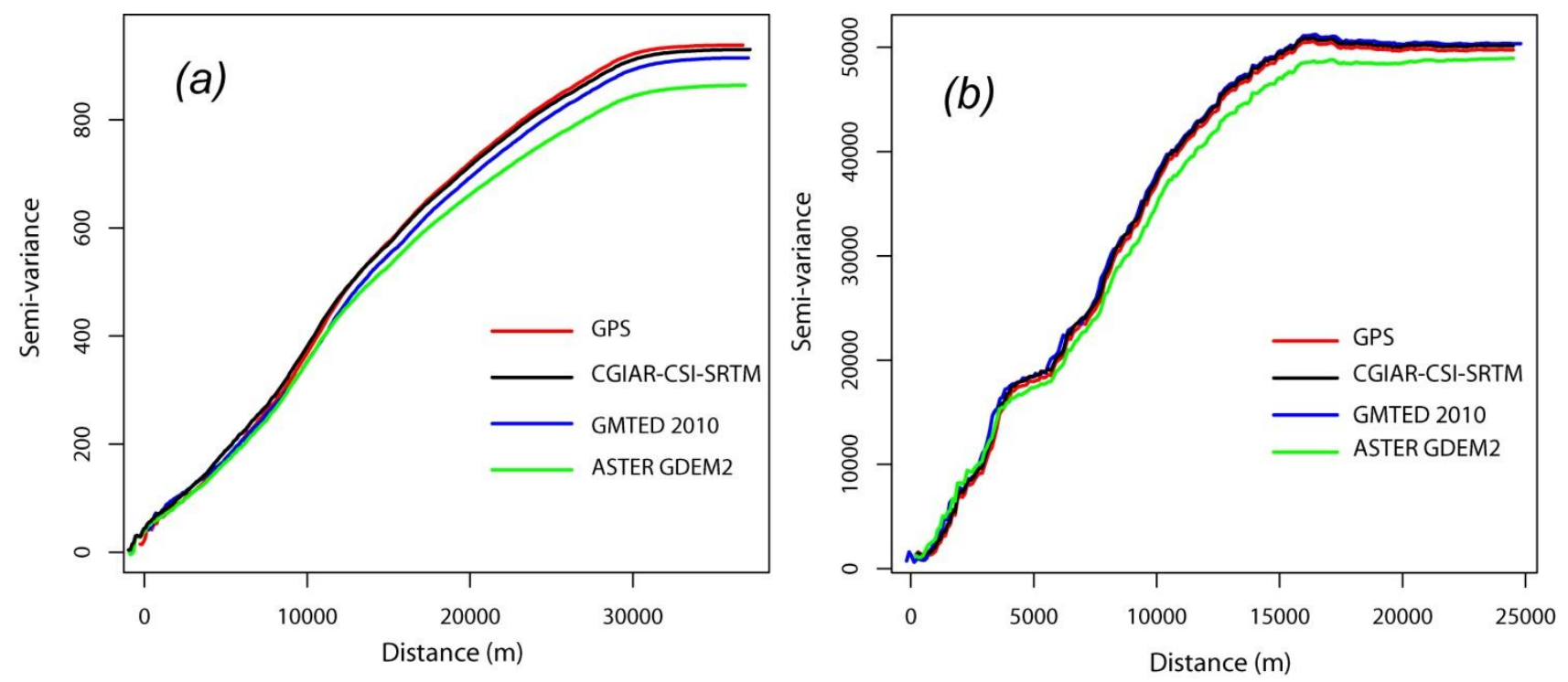

The correlation plots between GNSS data and each of the three DEMs obtained for both sites are shown in Figures 7 and 8a-c. As mentioned earlier, these plots are based on a selection of 328 and 60 GNSS points for Anaguid and Tebessa test sites, respectively. Results from site 1 (Figure 7a-c) indicate that SRTM v4.1 and GMTED2010 elevation values are slightly better correlated to the reference than ASTER. The correlation coefficients are 0.96, 0.99 and 0.97 for ASTER, SRTM v4.1 and GMTED2010, respectively. The plot for site 2 (Figure 8a-c) indicates, however, that the three DEMs have the same correlation coefficient with the reference elevation data. All stations extend the 
line of perfect fit, showing excellent coefficient of correlation $(r=0.99)$. This could be due to the number and distribution of selected points.

Figure 7. Summary statistics for Anaguid test site. Scatter plots of GNSS elevations vs. (a) ASTER GDEM2, (b) SRTM v4.1 and (c) GMTED2010. The fine red line stands for the line of perfect fit. Histograms of elevation errors and relevant descriptive statistics. (d) ASTER GDEM2 minus GNSS elevations, (e) SRTM v4.1 minus GNSS elevations and (f) GMTED2010 minus GNSS elevations. The solid red line represents the fitted density curve.
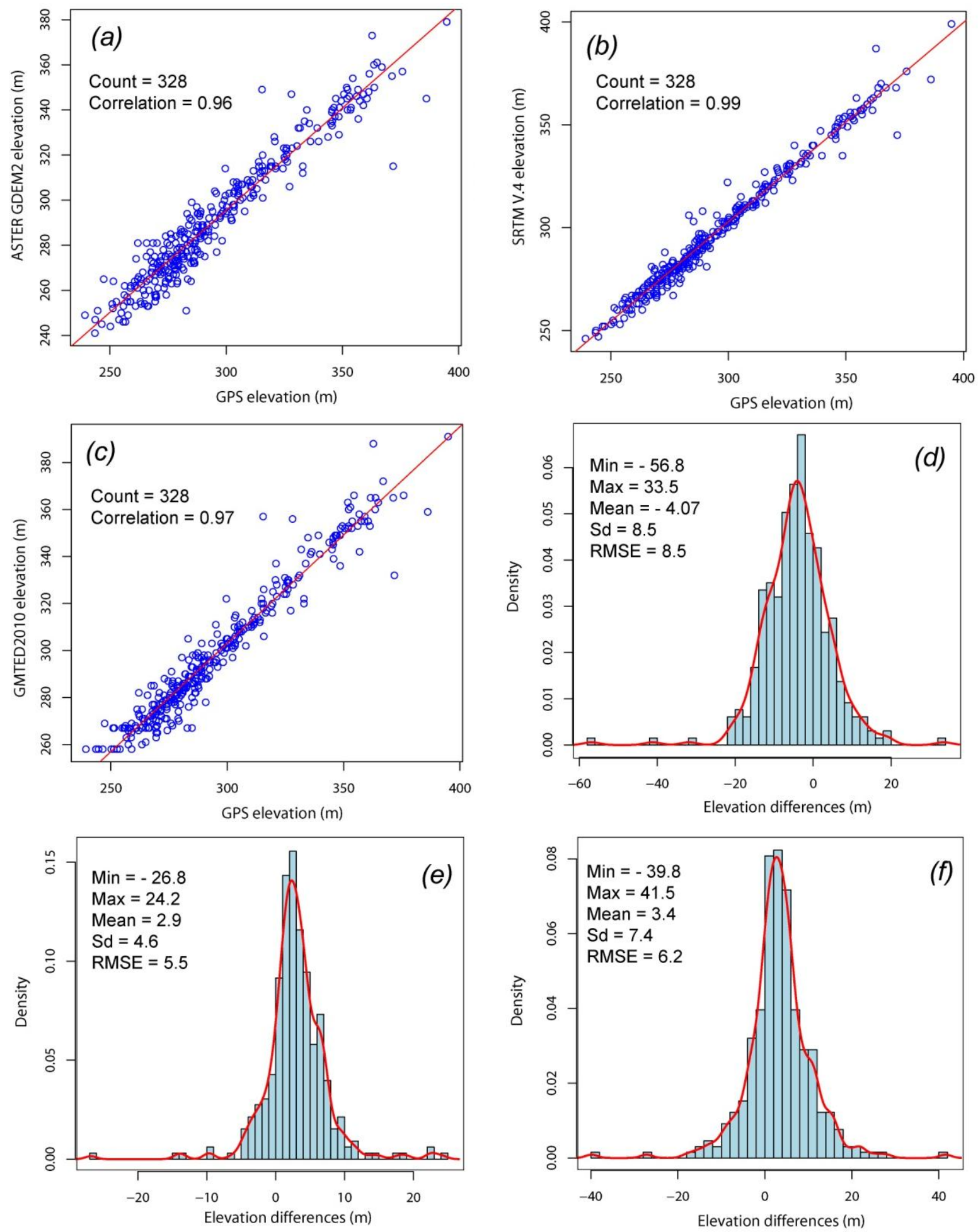
Figure 8. Summary statistics for Tebessa test site. Scatter plots of GNSS elevations vs. (a) ASTER GDEM2, (b), SRTM v4.1 and (c) GMTED2010. The red line stands for the line of perfect fit. Histograms of elevation errors and relevant descriptive statistics: (d) ASTER GDEM2 minus GNSS elevations, (e) SRTM v4.1 minus GNSS elevations and (f) GMTED2010 minus GNSS elevations. The solid red line represents the fitted density curve.
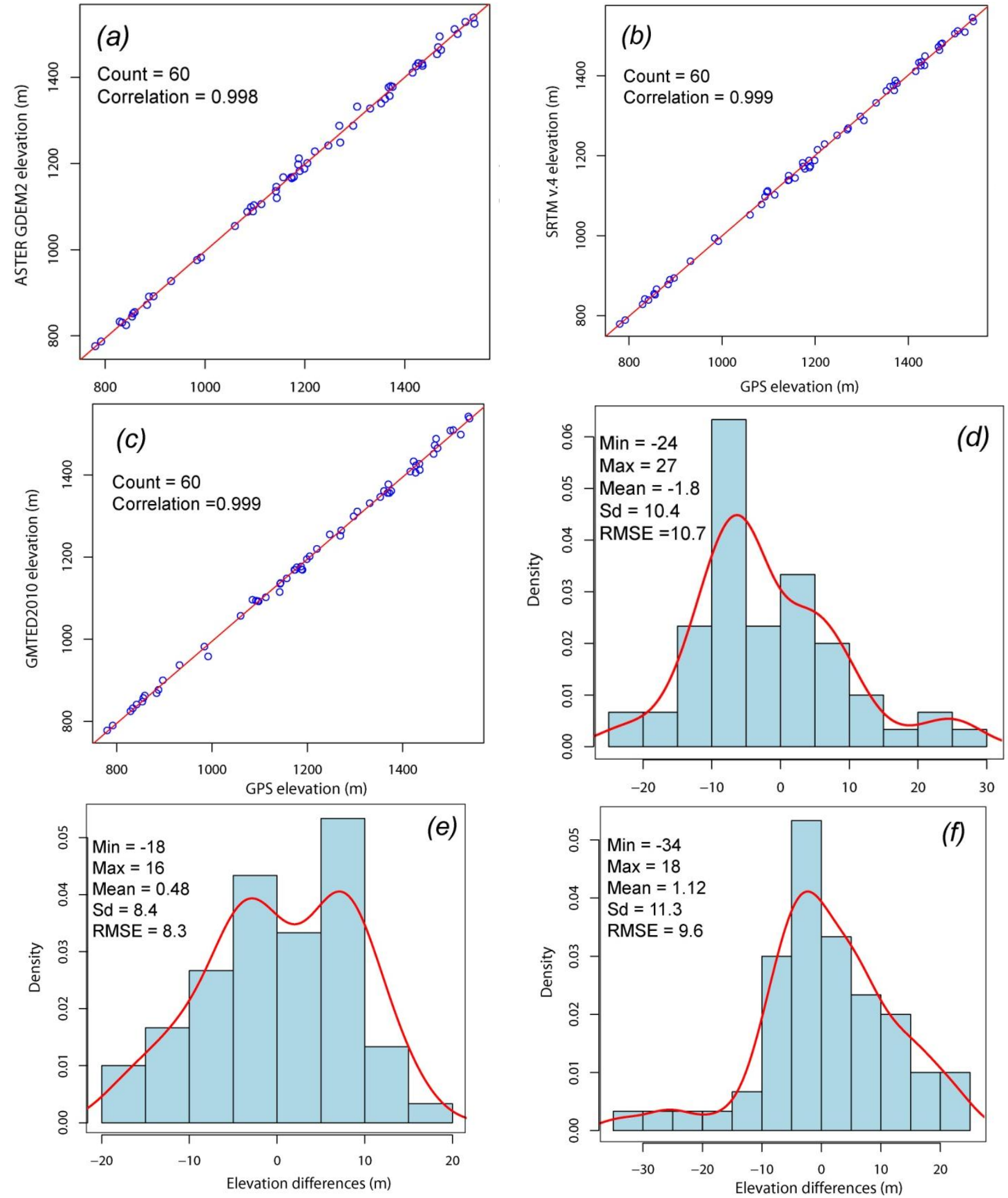
The histograms of the elevation differences between GNSS data and the corresponding DEM are presented in Figures 3 and $4 \mathrm{~d}-\mathrm{f}$. The Table 2 lists the minimum, maximum and mean error together with the RMSE and standard deviation values.

Table 2. Difference statistics of the study sites (Units in meters).

\begin{tabular}{ccccccccccc}
\hline \multirow{2}{*}{ Statistics } & \multicolumn{4}{c}{ Before Removing Outliers } & \multicolumn{5}{c}{ After Removing Outliers } \\
& Min & Max & Mean & SD & RMSE & Min & Max & Mean & SD & RMSE \\
\hline & & \multicolumn{9}{c}{ Anaguid test site } \\
\hline ASTER-GNSS & -56.8 & 33.5 & -4.07 & 8.5 & 8.5 & -41.7 & 33.5 & -2.32 & 6.8 & 5.3 \\
SRTM-GNSS & -26.8 & 24.2 & 2.9 & 4.6 & 5.5 & -26.8 & 24.2 & 0.48 & 3.4 & 3.6 \\
GMTED-GNSS & -39.8 & 41.5 & 3.4 & 7.4 & 6.2 & -37.3 & 29.4 & 0.63 & 4.8 & 4.5 \\
\hline & \multicolumn{8}{c}{ Tebessa test site } \\
\hline ASTER-GNSS & -24 & 27 & -1.8 & 10.4 & 10.7 & -24 & 18 & -1.02 & 9.43 & 9.8 \\
SRTM-GNSS & -18 & 16 & 0.48 & 8.4 & 8.3 & -18 & 16 & 0.48 & 8.4 & 8.3 \\
GMTED-GNSS & -34 & 18 & 1.12 & 11.3 & 9.6 & -34 & 18 & 1.12 & 11.3 & 9.6 \\
\hline
\end{tabular}

The basic statistics of errors in ASTER show a negative mean error of $-4.07 \mathrm{~m}$ and $-1.8 \mathrm{~m}$ (i.e., biased negatively) for Anaguid and Tebessa test sites, respectively. The histograms of elevation differences (Figures 7d and 8d) present a slightly negative skew, indicating that the ASTER model underestimates the spatial distribution of terrain elevation, more pronounced on flat and less complex terrains (site 1) than in hilly and complex terrains (site 2). This underestimation of ASTER was noted in previous studies. Hirt et al. [23] reported a clear negative bias for ASTER with respect to GCPs.

SRTM errors show positive mean values of $2.9 \mathrm{~m}$ for the Anaguid and $0.48 \mathrm{~m}$ for the Tebessa test sites. The histograms of the differences between SRTM DEMs and the GNSS reference (Figures 7e and 8e) closely follow a normal distribution. However, there is a slight bias towards positive values. The elevation value in the SRTM DEMs is greater than the GNSS value. This can be explained by the difference between the surface model provided by the SRTM measurements and the ground elevations measured by the GNSS survey. These observations were further confirmed in many previous studies [27,33], but debated by Li et al. [28] and Zhao et al. [25] who did not find a positive bias for SRTM.

The statistical values of errors in GMTED2010 model present also a positive mean error of $3.4 \mathrm{~m}$ and $1.12 \mathrm{~m}$ for Anaguid and Tebessa test sites, respectively. The histograms (Figures $7 \mathrm{f}$ and $8 \mathrm{f}$ ) present frequencies of positive errors greater than those of the negative errors. A large positive bias is clearly observed in both histograms, indicating that the GMTED2010 overestimated the terrain elevation. A general overestimation of terrain elevation by the systematic subsample GMTED2010 with respect to 1.6 million control points was reported by Danielson and Gesch [39].

Figure 9 shows the Q-Q plots of elevation errors in three datasets for each test site. These graphics were generated using "qqplot" commend in the optional "car" $\mathrm{R}$ add-on package [52]. The default options of the qqplot procedure automatically generated a reference line, along with upper and lower $95 \%$ confidence intervals for the plot. 
Figure 9. Q-Q plots for the Anaguid test site ( $a, b$ and $c$ ) showing the error distribution for (a) ASTER GDEM2, (b) SRTM v4.1 and (c) GMTED2010. Q-Q plots for the Tebessa test site showing the error distribution for (d) ASTER GDEM2, (e) SRTM v4.1 and (f) GMTED2010. The solid and dashed red lines represent theoretical normal distribution and $95 \%$ confidence intervals, respectively.
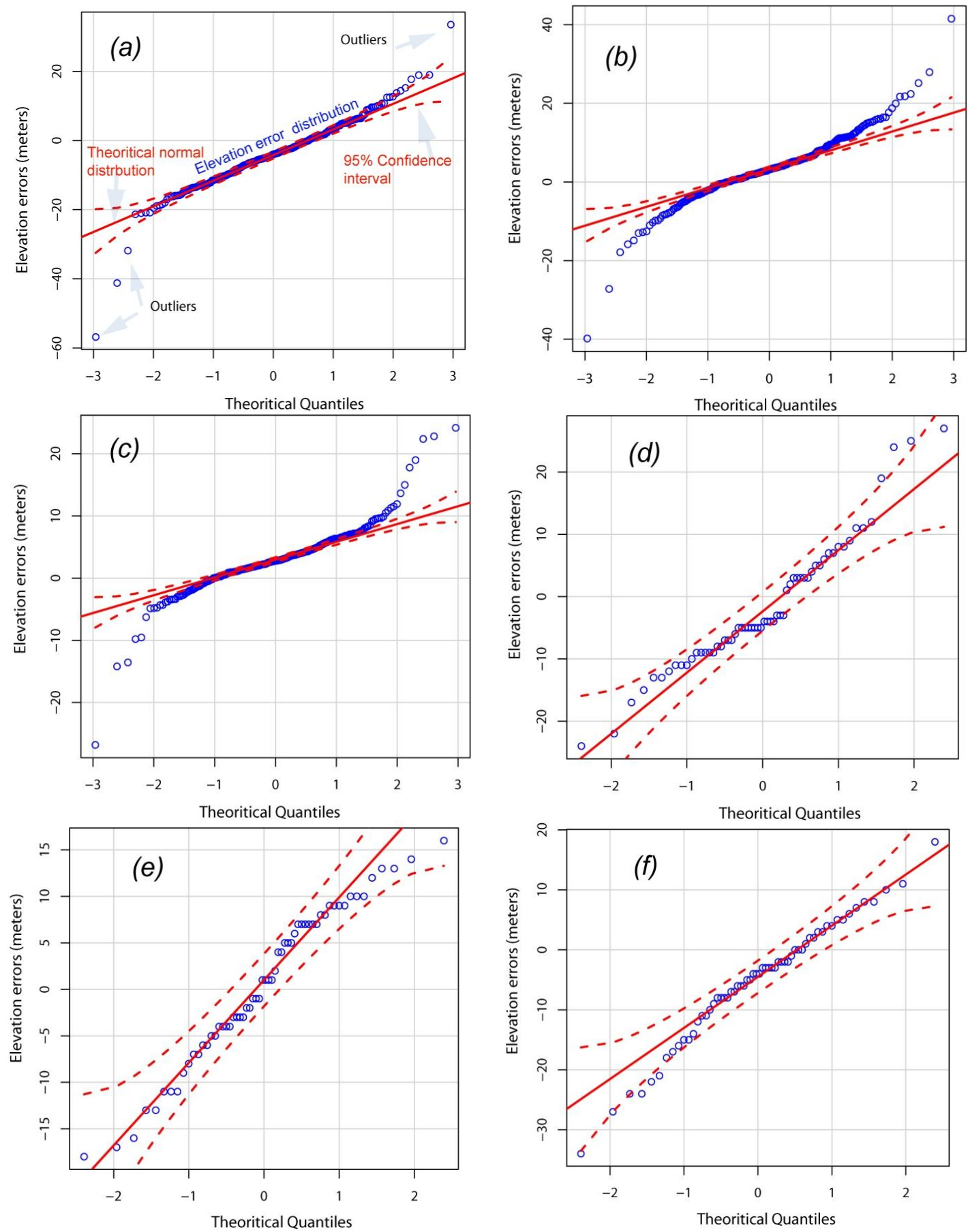

The Q-Q plots for the Tebessa test site (Figure 9d-f) show best-fit linear relationship with the exception of few points on both ends of the distribution. However, the Q-Q plots for site 1 (Figure 9a-c) expose a sigmoid-type function with a considerable deviation from the straight line, indicating that the data are not normally distributed. Many observations show a strong deviation from the $95 \%$ confidence limits, suggesting presence of outliers and gross errors affecting the data. A simple 
approach based on Li et al. [28] was applied in this case study. It consists to use an $3 \sigma$ elimination empirical rule [28]: (1) DEM was corrected by shifting the bias between DEM and GPS (i.e., (1) DEMcorrected = DEM - Mean (DEM-GPS); (2) the standard deviation between the corrected DEM and GPS was calculated; (3) all pixels with differences between the corrected DEM and GPS more than three times the standard deviation are considered to be gross errors, therefore removed.

After eliminating outliers, the comparison of the accuracy of all DEMs for both sites was recomputed. The $3 \sigma$ elimination empirical approach greatly increased the accuracy of all DEMs, as indicated by all validation statistics reported in Table 2. For Anaguid test site, the RMSE value is improved by $3.2 \mathrm{~m}$ for ASTER, $1.9 \mathrm{~m}$ for SRTM and $1.7 \mathrm{~m}$ for GMTED2010.The SRTM model continues to yield a better accuracy $(\mathrm{RMSE}=3.6 \mathrm{~m})$ than GMTED2010 $(\mathrm{RMSE}=4.5 \mathrm{~m})$ and ASTER $($ RMSE $=5.3 \mathrm{~m})$. Both SRTM and GMTED2010 models present a mean error near to zero and an RMSE approximately equal to the standard deviation, indicating that the estimator for these datasets is unbiased. For Tebessa test site, the RMSE measured for elevation differences between SRTM-GNSS is $8.3 \mathrm{~m}$, while this value for ASTER-GNSS is $9.8 \mathrm{~m}$ and $9.6 \mathrm{~m}$ for GMTED2010-GNSS. Consequently, the SRTM DEM is more accurate than GMTED2010 and ASTER.

The vertical accuracy assessment of the three DEMs reveals that the SRTM data shows a better vertical accuracy than both ASTER GDEM2 and GMTED2010 for both sites. Surprisingly, the vertical accuracy of ASTER GDEM2 is less than the accuracy of GMTED2010, as it achieved a much higher RMSE compared to GMTED2010. The better accuracy of SRTM over ASTER has been noted in previous studies. Those results were contradicted by Mukherjee et al. [30] who mentioned that ASTER gives better accuracy (Table 3).

Table 3. Varying reported height accuracies for the ASTER GDEM2 and SRTM v4.1 DEMs (unit in meters).

\begin{tabular}{cccccc}
\hline \multirow{2}{*}{ Studies } & \multirow{2}{*}{ Study Areas } & \multicolumn{2}{c}{ ASTER GDEM2 } & \multicolumn{2}{c}{ SRTM v4.1 } \\
& Karian dam, Indonesia & N/A & 5.68 & N/A & 3.25 \\
Suwandana et al. [27] & RMSE & ME & RMSE \\
Rexer and Hirt [33] & Australia (Bare areas) & -4.22 & 8.05 & 2.69 & 3.43 \\
Pulighe and Fava [34] & Southern Sardinia, Italy & N/A & 12.95 & N/A & N/A \\
Li et al. [28] & China ( Tibetan Plateau) & -5.9 & 14.1 & 0.9 & 8.6 \\
Mukherjee et al. [30] & Shiwalik Himalaya, India & -2.58 & 6.08 & -2.94 & 9.2 \\
\hline
\end{tabular}

However, the large variation in average global height precision found in the examined DEMs literature seems to indicate that the vertical precision of the DEMs depends considerably on several parameters (i.e., location, reference data errors, terrain characteristics and surface feature properties). Therefore, it is recommended to perform an in depth investigations about those factors. In addition, a quick look at Table 3 reveals that the RMSE values of 5.3-3.6 m for SRTM v4.1 and ASTER for Anaguid site are very similar to those reported by Rexer and Hirt [33] and Suwandana et al. [27], but much lower than those of Li et al. [28]. However, this study is the first investigation to report the lower accuracy of ASTER compared to GMTED2010 data. An explanation for this finding can be attributed to the accuracy of the original data source used to produce GMTED2010. According to Danielson and Gesch [36], all of the 7.5-arc-second GMTED2010 products derived from the 1-arc-second SRTM DTED2 void-filled data, like our study areas, have an RMSE around of $9.7 \mathrm{~m}$ that was stated for the 
1-arc-second SRTM mission specification. However, many authors have attributed the cause of the relatively low accuracy of ASTER to the varied stacking numbers from place to place. The stacking number (NUM files) is included in the quality assessment (QA) file and corresponds to the number of stacked ASTER DEM scenes used to compute the final ASTER elevation value for the corresponding pixel in the DEM file [21]. Theoretically, the ASTER RMSE should decrease with increasing stack number. Miliaresis and Paraschou [25] have found that the vertical accuracy of ASTER GDEM2, relatively, is better with increasing stack number and increasing number of grid points used per NUM class. According to ASTER GDEM2 validation team [34], an increase in the number of scenes reduces error significantly between 1 and 10 scenes, but there is little improvement after about 15 scenes.

\section{Conclusions}

This study investigated the quality of three new digital elevation models ASTER GDEM2, CGIAR-CSI SRTM v4.1 and GDEMTED2010 over two different geographical localities in Tunisia and Algeria, all of which are available free of charge. First, the basic characteristics of the models were described. Then, comparisons among the three models were presented and their respective vertical accuracy was estimated by means of comparisons against GNSS reference data. Finally, model differences were discussed from statistical viewpoint. For the assessment of the accuracy, statistical methods based on frequency histograms and Q-Q plots were presented and the error characteristics in three datasets for each test site were investigated. After outliers' removal using a $3 \sigma$ elimination rule, the validation statistics were recomputed for each DEM and for both sites. The results for site 1 reveal a RMSE value of about $5.3 \mathrm{~m}$ of ASTER GDEM2 vs. GNSS data. The RMSE value is higher than that computed for SRTM (3.6 m) and GMTED2010 (4.5 m). The results for site 2 show RMSE of terrain elevation ranging from $8.3 \mathrm{~m}$ for the SRTM v4.1 to $9.8 \mathrm{~m}$ for ASTER GDEM2. A RMSE of $9.6 \mathrm{~m}$ was calculated for the recently available GMTED2010. For both sites, the results suggest that ASTER GDEM2 slightly underestimates altitudes, while this trend was not found in SRTM or GMTED2010 DEM. The significant differences between the two test sites can probably be attributed to vegetation coverage. Tebessa is more vegetated (brushes and trees) than the Anaguid area. Both sensors, ASTER and SRTM are sensitive to the top of the canopy. That is why the negative bias of ASTER is not as severe (only $-1.8 \mathrm{~m}$ ) and the RMSE values of SRTM, GMTED2010 and ASTER in Tebessa are higher, in general. In conclusion, this study has demonstrated the importance of computing validation statistics for DEM before and after removing outliers. Further investigation can be made to evaluate the outliers and reasons for their occurrence.

\section{Acknowledgments}

Authors express their sincere gratitude to NASA, NIMA, METI, USGS and CGIAR-CSI for making this work possible by processing and distributing free the DEMs data to the scientific community. The authors would like to thank three anonymous reviewers for their helpful comments. The authors are grateful to Ali Sdiri, assistant professor at National School of Engineer of Sfax, Tunisia, for improving the English language of the paper. 


\section{Author Contributions}

Both authors have contributed equally to this manuscript.

\section{Conflicts of Interest}

The authors declare no conflict of interest.

\section{References}

1. Honghai, Q.; Altinakar, M.S.A. GIS-based decision support system for integrated flood management under uncertainty with two dimensional numerical simulations. Environ. Model. Softw. 2011, 26, 817-821.

2. Grohmann, C.H.; Sawakuchi, A. Influence of cell size on volume calculation using digital terrain models: A case of coastal dune fields. Geomorphology 2013, 180-181, 130-136.

3. Vassilopouloua, S.; Hurnia, L.; Dietrichb, V.; Baltsaviasc, E.; Paterakic, M.; Lagiosd, E.; Parcharidis, L. Orthophoto generation using IKONOS imagery and high resolution DEM: A case study on volcanic hazard monitoring of Nisyros Island (Greece). ISPRS J. Photogramm. Remote Sens. 2002, 57, 24-38.

4. Lee, S.J.; Komatitsch, D.; Huang, B.; Tromp, J. Effects of topography on seismic-wave propagation: An example from northern Taiwan. Bull. Seismol. Soc. Am. 2009, 99, 314-325.

5. Nekhay, O.; Arriaza, M.; Boerboom, L. Evaluation of soil erosion risk using analytic network process and GIS: A case study from Spanish mountain olive plantations. J. Environ. Manag. 2009, 90, 3091-3104.

6. Rebai, N.; Achour, H.; Chaabouni, R.; Bou Kheir, R.; Bouaziz, S. DEM and GIS analysis of sub-watersheds to evaluate relative tectonic activity. A case study of the North-south axis (Central Tunisia). Earth Sci. Inform. 2013, 6, 187-198.

7. Moore, I.D.; Grayson, R.B.; Ladson, A.R. Digital terrain modelling: A review of hydrological, geomorphological, and biological applications. Hydrol. Processes 1991, 5, 3-30.

8. Hengl, T.; Reuter, H. Developments in Soil Science. In Geomorphometry: Concepts, Software, Applications; Elsevier: Amsterdam, The Netherlands, 2008; Volume 33, pp. 26-29.

9. Li, J.; Chapman, M.A.; Sun, X. Validation of Satellite-Derived Digital Elevation Models from In-Track IKONOS Stereo Imagery; Ontario Ministry of Transportation: Toronto, ON, Canada, 2006.

10. Fisher, P.F.; Tate, N.J. Causes and consequences of error in Digital Elevation Models. Prog. Phys. Geogr. 2006, 30, 467-489.

11. Gong, J.; Li, Z.; Zhu, Q.; Sui, H.; Zhou, Y. Effects of various factors on the accuracy of DEMs: An intensive experimental investigation. Photogram. Eng. Remote Sens. 2000, 66, 1113-1117.

12. Hebeler, F.; Purves, R.S. The influence of elevation uncertainty on derivation of topographic indices. Geomorphology 2009, 111, 4-16.

13. Moreira, A.; Krieger, G.; Hajnsek, I.; Hounam, D.; Werner, M.; Riegger, S.; Settelmeyer E. TanDEM-X: A TerraSAR-X Add-On Satellite for Single-Pass SAR Interferometry. In 
Proceedings of the 2004 IEEE International Geoscience and Remote Sensing Symposium, Anchorage, AK, USA, 20-24 September 2004; Volume 2, pp. 1000-1003.

14. Manfreda, S.; Di Leo, M.; Sole, A. Detection of flood-prone areas using Digital Elevation Models. J. Hydrol. Eng. 2011, 16, 781-790.

15. Gonga-Saholiariliva, N.; Gunnell, Y.; Petit, C.; Mering, C. Techniques for quantifying the accuracy of gridded elevation models and for mapping uncertainty in digital terrain analysis. Prog. Phys. Geogr. 2011, 35, 739-764.

16. Kasser, M.; Yves, E. Digital Photogrammetry; Taylor \& Francis: London, UK, 2001; p. 351.

17. Jarvis, A.; Rubiano, J.; Nelson, A.; Farrow, A.; Mulligan, M. Practical Use of SRTM Data in the Tropics: Comparisons with Digital Elevation Models Generated from Cartographic Data; International Centre for Tropical, Agriculture (CIAT): Cali, Columbia, 2004; p. 32.

18. Miliaresis, G.C.; Paraschou, C.V.E. Vertical accuracy of the SRTM DTED level 1 of Crete. Int. J. Appl. Earth Obs. Geoinfor. 2005, 7, 49-59.

19. Rodriguez, E.; Morris, C.S.; Belz, J.E. A global assessment of the SRTM performance. Photogramm. Eng. Remote Sens. 2006, 72, 249-260.

20. Reuter, H.I.; Nelson, A.; Strobl, P.; Mehl, W.; Jarvis, A. A First Assessment of ASTER GDEM Tiles for Absolute Accuracy, Relative Accuracy and Terrain Parameters. In Proceedings of the 2009 IEEE International Geoscience and Remote Sensing Symposium, Cape Town, South Africa, 12-17 July 2009.

21. Nikolakopoulos, K.G.; Kamaratakis, E.K.; Chrysoulakis, N. SRTM vs. ASTER elevation products. comparison for two regions in Crete, Greece. Int. J. Remote Sens. 2006, 27, 4819-4838.

22. Abrams, M.; Bailey, B.; Tsu, H.; Hato. M. The ASTER global DEM. Photogramm. Eng. Remote Sens. 2010, 76, 344-348.

23. Hirt, C; Filmer, M.S; Featherstone, W.E. Comparison and validation of the recent freely available ASTER-GDEM ver1, SRTM Ver4.1 and GEODATA DEM-9s Ver3 Digital Elevation Models over Australia. Aust. J. Earth Sci. 2010, 57, 337-347.

24. Mouratidis, A.; Briole, P.; Katsambalos, K. SRTM 3" DEM (Versions 1, 2, 3, 4) validation by means of extensive kinematic GPS measurements: A case study from north Greece. Int. J. Remote Sens. 2010, 31, 6205-6222.

25. Zhao, G.; Xue, H.; Ling, F. Assessment of ASTER GDEM Performance by Comparing with SRTM and ICESat/GLAS Data in Central China. In Proceedings of the 18th International Conference on Geoinformatics, Beijing, China, 18-20 June 2010.

26. Miliaresis, G.C.; Paraschou, C.V.E. An evaluation of the accuracy of the ASTER GDEM and the role of stack number: A case study of Nisiros Island, Greece. Remote Sens. Lett. 2011, 2, 127-135.

27. Suwandana, E.; Kawamura, K.; Sakuno; Y.; Kustiyanto, E.; Raharjo, B. Evaluation of ASTER GDEM2 in comparison with GDEM1, SRTM DEM and topographic-map-derived DEM using inundation area analysis and RTK-dGPS data. Remote Sens. 2012, 4, 2419-2431.

28. Li, P.; Shi, C.; Li, Z.; Muller, J.P.; Drummond, J.; Li, X.; Li, T.; Li, Y.; Liu, J. Evaluation of ASTER GDEM using GPS benchmarks and SRTM in China. Int. J. Remote Sens. 2013, 34, 1744-1771. 
29. Kolecka, N.; Kozak, J. Assessment of the accuracy of SRTM C- and X-Band high mountain elevation data: A case study of the Polish Tatra Mountains. Pure Appl. Geophys. 2013, doi:10.1007/s00024-013-0695-5.

30. Mukherjee, S.; Joshi, P.K.; Mukherjee, S.; Ghosh, A.; Garg, R.D.; Mukhopadhyay, A. evaluation of vertical accuracy of open source Digital Elevation Model (DEM). Int. J. Appl. Earth Obs. Geoinf. 2013, 21, 205-217.

31. Forkuor, G.; Maathuis, B. Comparison of SRTM and ASTER Derived Digital Elevation Models over Two Regions in Ghana-Implications for Hydrological and Environmental Modeling. In Studies on Environmental and Applied Geomorphology; Piacentini, T., Ed.; InTech: Rijeka, Croatia, 2012; pp. 219-240.

32. Marti, U. Comparison of SRTM Data with the National DTMs of Switzerland. In Proceedings of GGSM 2004 IAG International Symposium Porto, Porto, Portugal, 30 August-3 September 2004.

33. Rexer, M.; Hirt, C. Comparison of free high resolution digital elevation data sets (ASTER GDEM2, SRTM v2.1/v4.1) and validation against accurate heights from the Australian National Gravity Database. Aust. J. Earth Sci. 2014, 61, 213-226.

34. Pulighe, G.; Fava, F. DEM extraction from archive aerial photos: Accuracy assessment in areas of complex topography. Eur. J. Remote Sens. 2013, 46, 363-378.

35. Durozoy, M.G. Feuille Géologique de Tebessa (n²06) au 1/50000; Service de la Carte Géologique de l'Algérie: Tebessa, Algérie, 1953.

36. ASTER GDEM Validation Team. ASTER Global DEM Validation-Summary Report. Available online: http://www.ersdac.or.jp (accessed on 19 October 2012).

37. ASTER GDEM Validation Team. ASTER Global Digital Elevation Model Version 2-Summary of Validation Results 2011. Available online: https://www.lpdaac.usgs.gov/ (accessed on 9 January 2013).

38. Jarvis, A.; Reuter, H.I. Nelson, A.; Guevara. E. Hole-Filled SRTM for the Globe Version 4. CGIAR-CSI SRTM $90 \mathrm{~m}$ Database 2008. Available online: http://srtm.csi.cgiar.org (accessed on 1 July 2012).

39. Danielson, J.J.; Gesch, D.B. Global Multi-Resolution Terrain Elevation Data 2010 (GMTED2010); U.S. Geological Survey Open-File Report; U.S. Geological Survey: Sioux Falls, SD, USA, 2011.

40. Maune, D.F., Ed. Digital Elevation Model Technologies and Applications: The DEM User Manual, 2nd ed.; Asprs Pubns: Bethesda, MD, USA, 2007.

41. ASPRS Lidar Committee. ASPRS Guidelines Vertical Accuracy Reporting for Lidar Data, 2004; Available online: http://www.asprs.org/society/committees/lidar/Downloads/Vertical_Accuracy_ Reporting_for_Lidar_Data.pdf (accessed on 28 January 2009).

42. Leica Geosystems. Leica GRX 1200 Series: Technical Data; Leica Geosystems AG: Heerbrugg, Switzerland, 2006.

43. Trimble. GeoExplorer 6000 Series User Guide; Trimble Navigation: Sunnyvale, CA, USA, 2011.

44. Kaplan, D.; Hegarty, C.J. Understanding GPS: Principles and Applications; Artech House: Boston, London, 2006; p. 32. 
45. Kaya, F.A.; Saritas, M. A Computer Simulation of Dilution of Precision in the Global Positioning System Using Matlab. In Proceedings of the 4th International Conference on Electrical and Electronic Engineering, Bursa, Turkey, 7-11 December2005.

46. Lemoine, F.G.; Smith, D.E.; Kunz, L.; Smith, R.; Pavlis, E.C.; Pavlis, N.K.; Klosko, S.M.; Chinn, D.S.; Torrence, M.H.; Williamson, R.G.; et al. The Development of NASA GSFC and NIMA Joint Geopential Model. In Proceedings of the 1996 International Symposium on Gravity, Geoid, and Marine geodesy, Tokyo, Japan, 30 September-5 October 1996.

47. Environment Systems Research Institute ESRI. ArcGIS Software, Version 9.3; Environment Systems Research Institute: Redlands, CA, USA, 2008.

48. R Development Core Team. R: A Language and Environment for Statistical Computing; R Foundation for Statistical Computing: Vienna, Austria, 2009.

49. Pebesma, J.E. Multivariable geostatistics in S: The gstat package. Comput. Geosci. 2004, 30, 683-691.

50. Goovaerts, P. Geostatistics in soil science: State-of-the-art and perspectives. Geoderma 1999, 89, $1-45$.

51. Zandbergen, P.A. Positional accuracy of spatial data: Non-normal distributions and a critique of the national standard for spatial data accuracy. Trans. GIS 2008, 12, 103-130.

52. Höhle, J.H; Höhle, M. Accuracy assessment of Digital Elevation Models by means of robust statistical methods. ISPRS J. Photogramm. Remote Sens. 2009, 64, 398-406.

53. Fox, J.; Weisberg, H.S. An R Companion to Applied Regression; Sage Publications: Thousand Oaks, CA, USA; p. 472.

(C) 2014 by the authors; licensee MDPI, Basel, Switzerland. This article is an open access article distributed under the terms and conditions of the Creative Commons Attribution license (http://creativecommons.org/licenses/by/3.0/). 